\title{
在昆虫细胞中克隆与表达人白细胞介素 $6^{*}$
}

\author{
赵春文 王嘉策** 肖定华 马贤凯
}

(军事医学科学院基础医学研究所, 北京 100850)

摘要

本文利用 DNA 合成及 PCR 技术对人白细胞介素 6(hIL-6) CDNA 进行转译优化 与扩增, 并同杆状病毒载体 pVL1393 重组构建了 pVL- IL-6 载体; 通过磷酸钻共沉 淀法将 pVL・IL-6 DNA 与野生型首落银线夜蛾核型多角体病毒 (wtAcMNPV) DNA 共转染昆虫细胞 Sf9, 篮选出表达人 IL-6 的重组病 rAc- IL-6. 经 ELISA 定量测定 $\mathrm{rhIL}-6$ 表达水平约为 $1 \mu \mathrm{g} / \mathrm{ml} ; \mathrm{rhIL}-6$ 生物活性经 IL-6 依赖细胞系 TTD1 测定为 $10^{6} \mathrm{u} / \mathrm{ml}$.

\section{关筧词 hIL6、PCR、杆状病每、AcMNPV、SP9}

杆状病毒载体表达系统由于对人畜安全无害、外源基因容量大、表达水平高、表达产物的 抗原性、免疫原性与功能均类似天然产物, 因而在诸多表达系统中日益引人注目 ${ }^{[1]} . \mathrm{hILL}-6$ 是一 种能够调节免疫应答、急性反应 (acute phase reaction) 及造血功能, 在宿主防御机制中起核 心调节作用的极为重要的多功能细胞因子 ${ }^{[2]}$, 而其天然来源的量甚微不数需求. 因此, 我们选 择杆状病毒表达载体系统在屁虫细胞中进行 hIl-6 的表达研究.

\section{1 材 料 和 方 法}

\section{1 材料}

1.1.1 细胞株、载体与每株 E. coli RR1 及 E. coli JM101 为本室保存菌种; 含 hIL-6 cDNA 全长编码区的质粒 $\mathrm{pBMIL-6A}$ 由本室分离构建 ${ }^{[3]}$; 杆状病毒表达载体 $\mathrm{pVL1393}$ 系由 Luckow 惠渞; 草地夜蛾细胞 Sf9 及 AcMNPV E2 株自比利时国立农学院 (Gembloux, Belgium) 引进.

1.1.2 酶、试剂盒 BamHI $(10 u / \mu)$, EcoRI $(10 u / \mu l)$, Xhol $(10 u / \mu l)$ 均为 Boehringer Mannheim 公司产品; BglII $(>12 \mathrm{u} / \mu \mathrm{l})$ HindIII $(12 \mathrm{u} / \mu \mathrm{l})$ 为 New England Biolabs 公司产品;蛋白酶 $\mathrm{K}$ 购自 华美生物制品公司; 测序试剂盒购自 BioRad 公司. IL-6 ELISA 试剂盒为 Genzyme公司产品.

\section{2 方法}

\subsection{1 引物设计、合成与 PCR 扩增 依据 hIL-6 cDNA 编码区设计左侧引物：5' CGGGG.}

1992-08-10 收稳，1993-03-01 收修改稿.

*国家自然科学基金资助项目.

**联系人. 
ATCCAGATCTACCATGGACTCCTTCACAAG 3'，3'侧 16 个诚基与模板完全互补，5侧导 人两个酶切位点与优化转译起始序列. 右侧引物：5' CGCGGATCCGAATTCCTACTA-CATTTGCCGAA 3'，3'侧 14 个喊基与模板完全互补, 5' 侧导人两个酶切位点和一个终止密码 子, 按此设计用亚磷酰胺三酯法, 在 Cyclone Plus 双柱 DNA 自动合成仪中合成上述引物, 并 按我们改进的方法纯化合成产物 ${ }^{[4]}$. 尔后, 用此引物以 pBMIL-6A 为模板, PCR 扩增 $670 \mathrm{bp}$ hIl-6 cDNA 片段. 反应结束后取 $5 \mu \mathrm{l}$ 反应液检测扩增结果, 其余转移至一新管加 $5 \mu \mathrm{l}$ 蛋白酶 $\mathrm{K}(20 \mu \mathrm{g} / \mu \mathrm{l}) 50^{\circ} \mathrm{C}$ 消化 $1 \mathrm{~h}$, 等体积酚/氯仿、氯仿/异戊醇各抽提一次, 水相加 $1 / 10$ 体积 $3 \mathrm{~mol} / \mathrm{L}$ $\mathrm{NaAc}\left(\mathrm{pH} 4.8\right.$ ), 2.5 体积无水乙醇, $-20^{\circ} \mathrm{C}$ 沉淀过夜, 离心弃上清, $70 \%$ 乙醇洗沉淀, 真空干 燥, 溶于适量的 TE 缓冲液, $-20^{\circ} \mathrm{C}$ 冻存备用[?].

1.2.2 组载体 pVL・IL6 的构建及 DNA 测序均按分子克隆实验手册第 2 版进行 ${ }^{[6}$, 重 组方案见图 1.

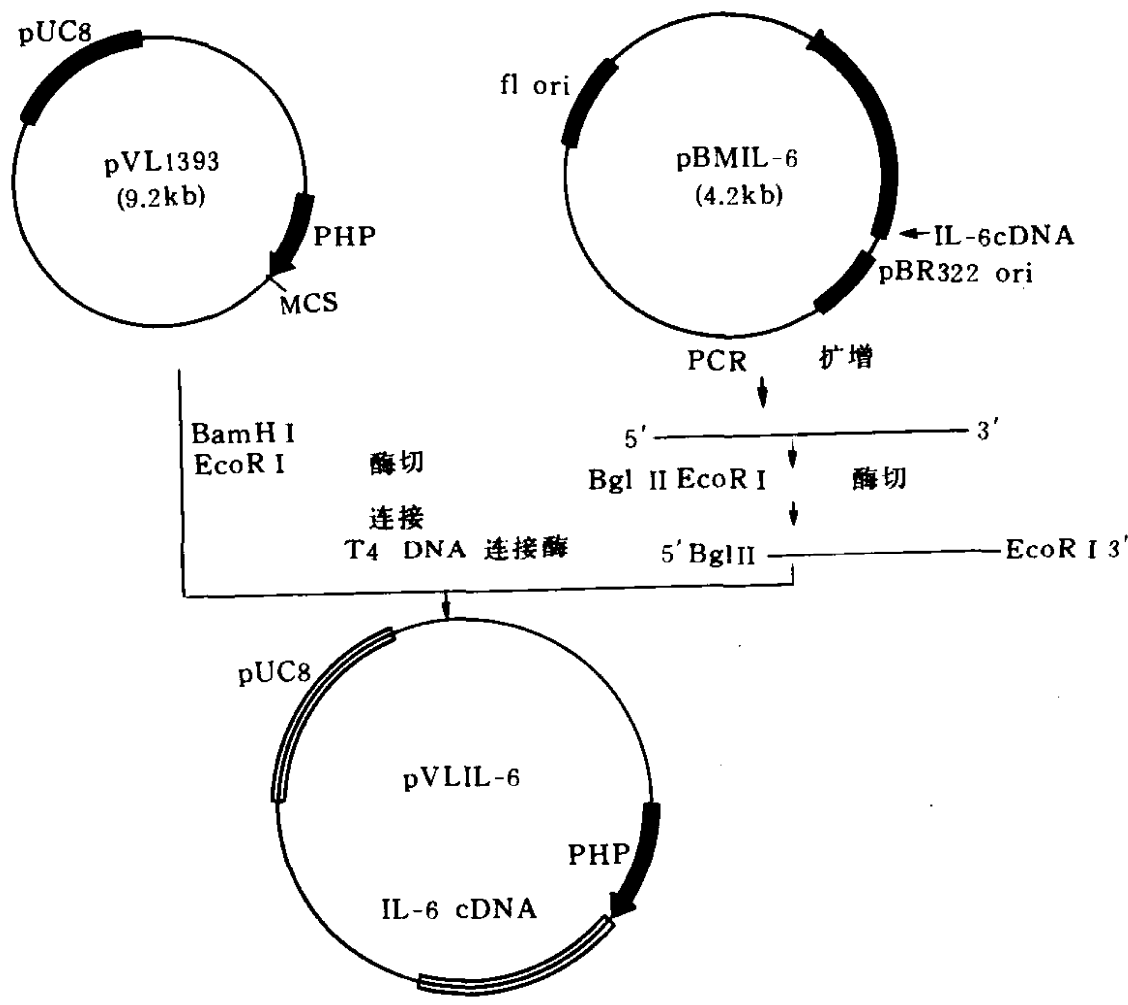

图 $1 \mathrm{pVL} \cdot$ IL-6构建示意图

\subsection{3 磁酸铝共沉淀将 pVL-IL-6 与 wt AcMNPV DNA 共转染导人 Sf9 细胞 ${ }^{[7}$.}

1.2.4 空斑管选按 Summers 法进行 ${ }^{[8]}$, 在低融点琼脂糖凝胶平板上形成空斑. 倒置显微镜 下观察空斑, 先用 $\times 40$ 低倍镜观察, 野生型病毒空斑 $\left(\mathrm{Oac}^{+}\right)$折光性强犹如晶体, 重组病毒空斑 $\mathrm{Orc}^{-}$呈暗灰色 ${ }^{19}$. 然后再用 $\times 400$ 高倍镜观察空斑中多角体量, 若无或很少可判定为重组病 毒 $O x^{-}$空斑并作标记, 用加样器吸头吸取空斑上之凝胶块置于灭菌的 Eppendorf 管内并加 $1 \mathrm{ml}$ 培养液悬浮, 再感染 Sf9 细胞, 进行下一轮空斑篮选、纯化及鉴定. 如此重复 3-4 次至全 部空琵均为重组病毒 $\mathrm{Oxc}^{-}$空斑为止.

\subsection{5 工组病每的监定 在 24 孔细胞培养板上每孔接种 $1 \mathrm{ml}$ 密度为 $1.5 \times 10^{4} / \mathrm{m} 1$ 的 $\mathrm{Sf} 9$ 细}


胞, 取可能的重组病毒空斑悬液感染孔内 $\mathrm{Sf} 9$ 细胞, $27^{\circ} \mathrm{C}$ 培养 $2-3$ 天 ${ }^{[109}$. 然后将各孔培养液 分别转移至另一 24 孔板相应的孔内, 在原培养板上每孔加 $200 \mu \mathrm{l} 0.5 \mathrm{~N} \mathrm{NaOH}$ 裂解细胞、变性 DNA, $5 \mathrm{~min}$ 后加 $40 \mu \mathrm{l} 5 \mathrm{~mol} / \mathrm{L} \mathrm{NH}_{4} \mathrm{Ac}$ 中和, 并利用 Multifold 点杂交装置将病毒 DNA 转印在 硝酸纤维素膜 (NCF) 上. 取出 $\mathrm{NCF}$, 漂洗、晾干, $80^{\circ} \mathrm{C}$ 焙烤 $2 \mathrm{~h}$ 使 DNA 固定在膜上. 然后同 ${ }^{32} \mathrm{P}$ 标记的 hIL-6 cDNA 探针杂交,放射自显影检测.

1.2.6 hIL-6 表达水平及生物活性测定用 Genzyme 公司产 IL-6 ELISA 定量检测盒 ${ }^{\left[{ }^{[1]}\right.}$ 及 IL-6 依赖细胞系 TTD1 ${ }^{3} \mathrm{H}-\mathrm{TdR}$ 半数最大掺人法进行 ${ }^{[12]}$.

\section{2 结 果}

\section{1 西组载体 pVL・ IL-6 的构建}

杆状病毒表达载体 pVL1393 的前体是带有多角体基因启动子的融合蛋白表达载体 pAc311, 经定点突变将多角体基因起始密码 ATG 变成 ATT 而组建成非融合蛋白表达载体 pVL941,再 改建成含多克隆位点 (MCS) 的 pVL1393 和 pVL1392, 见图 2. 取 5 $\mu \mathrm{g}$ pVL1393 DNA, BamHI EcoRI 双酶切, 低融点琼脂糖凝胶电泳回收带有 BamHI 和 EcoRI 粘性末端的线性化 pVL1393

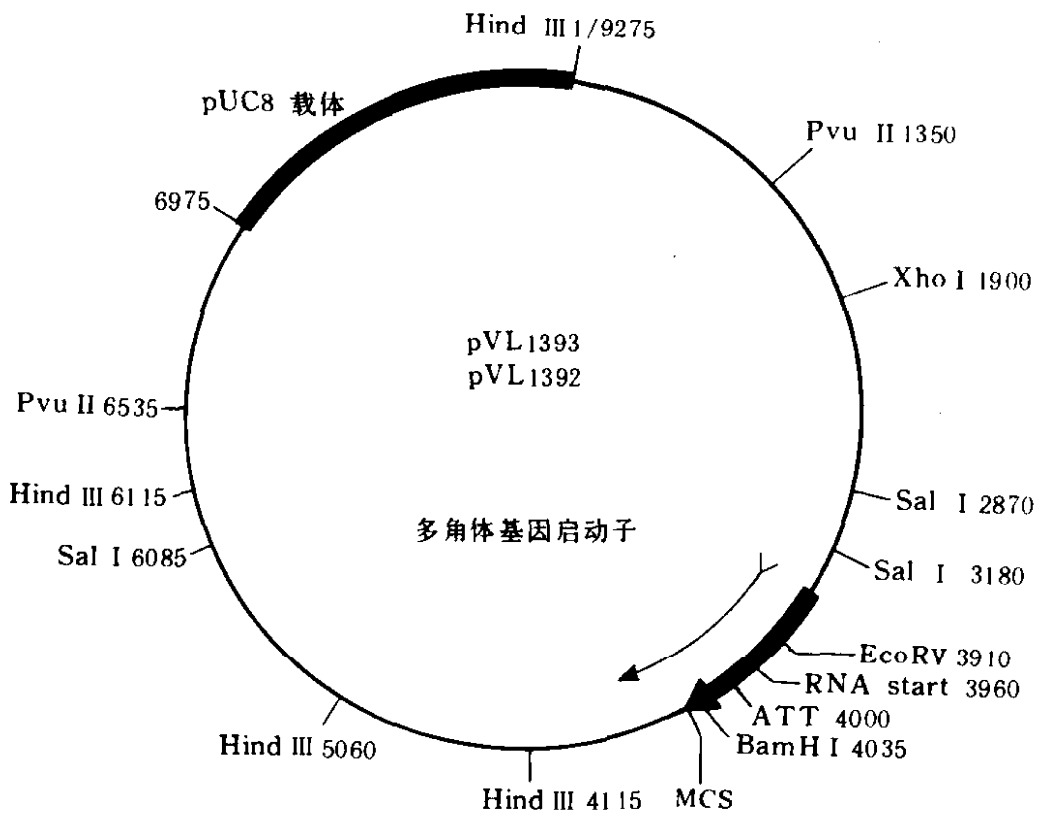

图 2 pVL1392和 pVL1393杆状病毒表达载体酶切图谱

DNA 约 $2 \mu \mathrm{g}$; PCR 扩增的 hIL-6 cDNA 片段则用 BglIIEooRI 双酶切并用同样方法回收带 有 BglI/EcoRI 粘性末端的片段约 $0.8 \mu \mathrm{g}$. 由于 BamHI 和 BglII 粘性末端互相匹配, 因此 hIL 6 cDNA 片段可以定向插人 pVL1393 载体. 载体与片段用 $\mathrm{T}_{4} \mathrm{DNA}$ 连接酶 $14^{\circ} \mathrm{C}$ 水浴连接过 夜, 转化 E.coli RR1 感受态细胞, 适量涂种于 LB/Ap 琼脂糖平血, $37^{\circ} \mathrm{C}$ 培养过夜得约 500 个 转化子. 快抽质粒 DNA 电泳检测, 任选 6 个分子量大于载体 pVL1393 的重组质粒, 再做酶切 电泳分析. 结果, pVL1393 经 HindIII/XhoI 双酶切产生 945, 1055, 1900, 2215 和 3160bp 5条 带; 重组质粒同样双酶切产生 945, 1055, 1900, 2881 和 $3160 \mathrm{bp} 5$ 条带, 其中 4 条与 pVL1393 的完全一样, 只是其中 2881(估计值 ) 比 pVL1393 的 2215 带增加了约 $660 \mathrm{bp}$, 恰好等于 hIL 6 
A 插人片段 (图 3). Southern 转印至硝酸纤维素膜再同 ${ }^{32} \mathrm{P}$ 标记 hIL-6 探针杂交, 放射自显

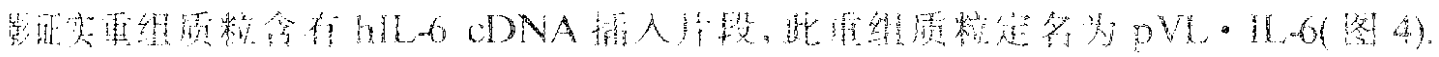
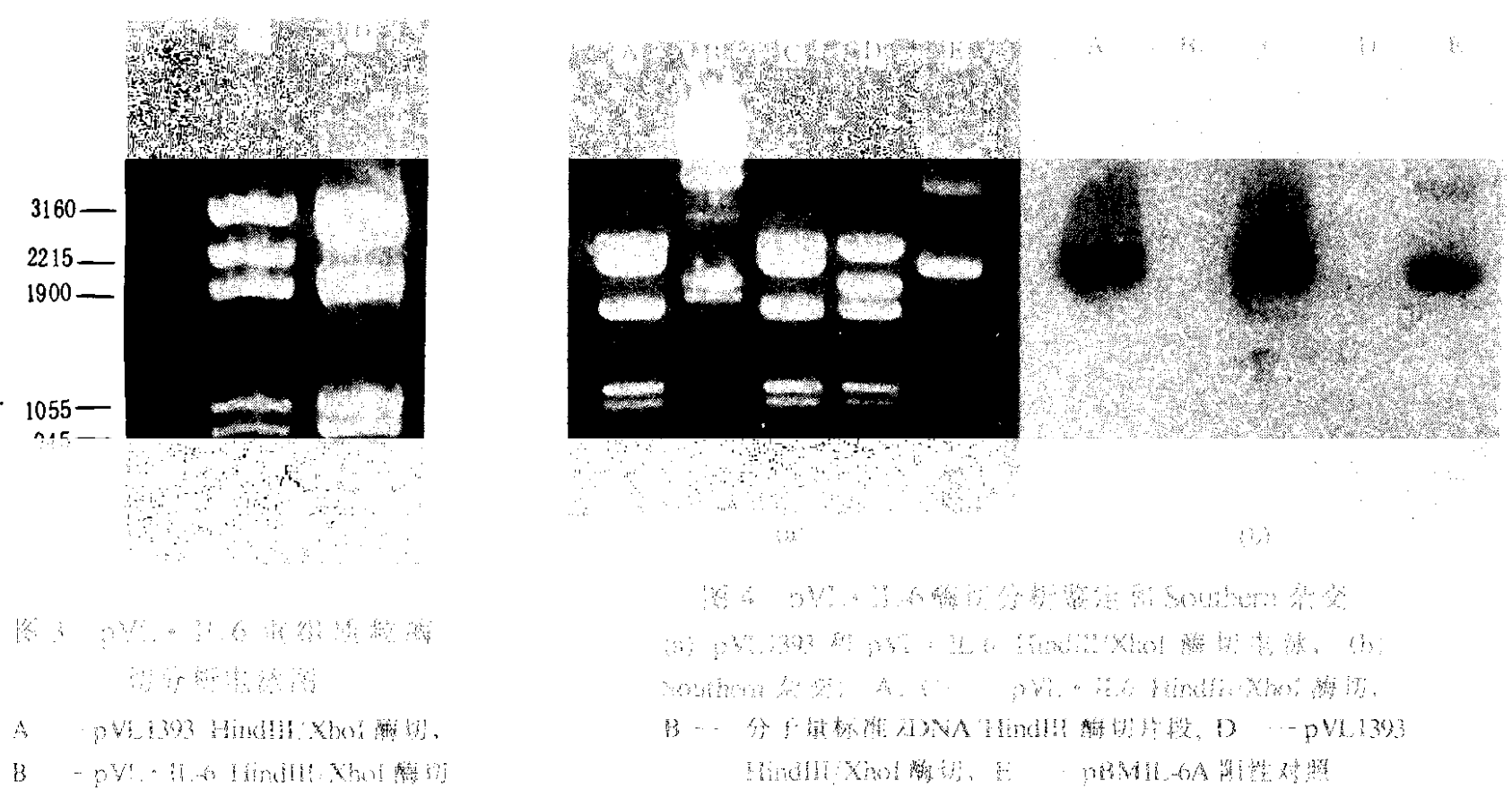

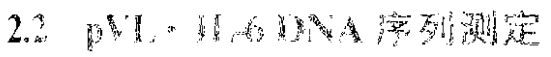

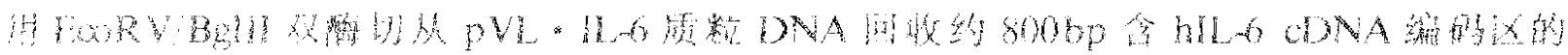

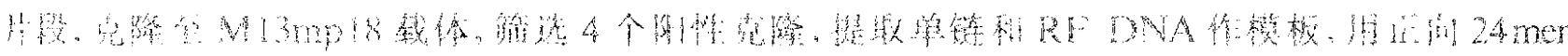


及反向 $22 \mathrm{mer}$ 通用引物, 利用 Promega 公司 $\mathrm{T}_{7}$ 测序酶系统进行脱氧终止法测序. 结果, $\mathrm{pVL}$ - IL-6 正链可读出 228 践基, 其中多角体基因部分 118 个碱基, 与文献发表的序列完全一 致 [1], 从中可见: (1) -77 位 TATA BOX 序列; (2)-57 位的多角体 mRNA 的 5'末端 AAA; (3) -48 位的转录起点 GTA; (4) 转译起始信号 ATG 变为 ATT. 在多角体基因序列之后 $+37-+42$ 处见-GGATCT 序列, 此即载体 BamHI 粘末端与片段 BglII 粘末端退火连接形成的序列. hIL-6 cDNA 正链部分 110 个诚基, 与载体连接处之后即为 ACCATGG, 证明 hIL-6 cDNA ATG 周围序列已由原来的 GCTATGA 突变为最优转译起始序列, 其后 97 个践基与文献报道的 hIL-6 cDNA 序列完全一致 (图 5). 负链测序结果发现两个终止密码子, 其中一个为 PCR 右 侧引物导人,终止密码前 197 个碱基与文献报道的 hIL-6 cDNA 相应序列完全一致(图 6) 综上所述表明引物设计、定点突变及定向重组均达预期目的.

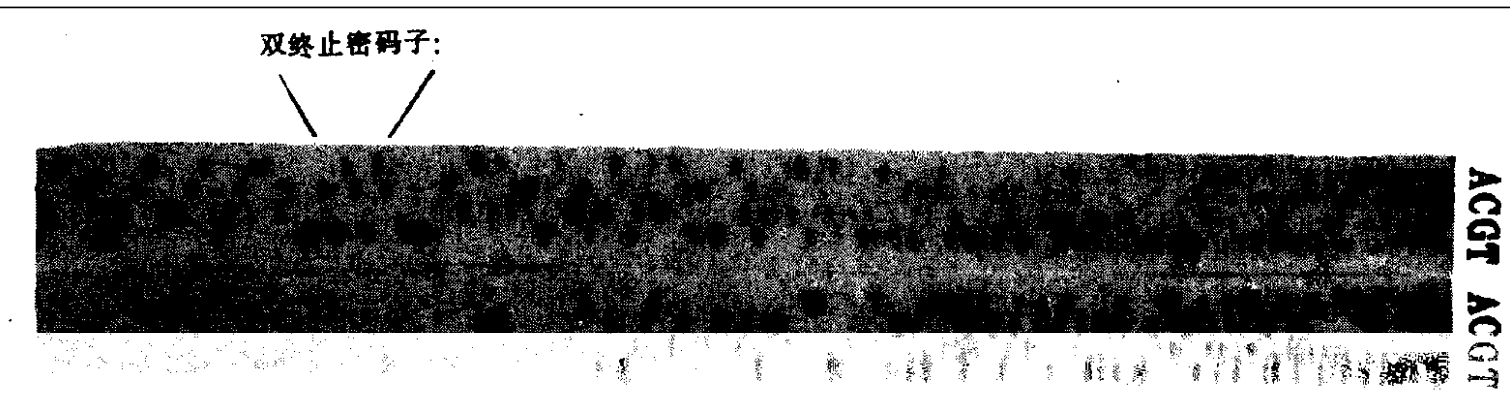

\section{CTACTACATT TGCCGAAGAG CCCTCAGGCT GGACTGCAGG AACTCCTTAA AGCTGCGCAG AATGAGATGA GTTGTCATGT CCTGCAGCCA CTGGTTCTGT GCCTGCAGCT TCGTCAGCAG GCTGGCATTT GTGGTTGGGT CAGGGGTGGT TATTGCATCT AGATTCTTTG CCTTTTTCTG CAGGAACTGG ATCAGGACTT TTG.,..... 3'}

图 $6 \mathrm{pVL} \cdot \mathrm{IL}$ - 正链 DNA 序列

图 7 用 ${ }^{32} \mathrm{P}$ 标记的 hIl-6 CDNA 针杂交篮 选重组阳性病毒 A3 - pVL1393 阴性对照, F2 和 F6 - pBMIL-6A, M13mpIL-6 阳性对照

\section{3 工组病每 rAc・I-6 的端选与监定}

pVL・IL-6 与 wtAcMNPV 共转染 Sf9 细胞,经 空斑篮选共挑出 24 个多角体阴性 $\left(\mathrm{Ooc}^{-}\right)$病毒空 斑. 用 ${ }^{32} \mathrm{P}$ 标记的 hIL-6 cDNA 探针点杂交证明大 部分为阳性,其中 5 株点杂信号最强 (图 7), 此重 组 IL-6 杆状病毒定名为 rAc・IL6.

\section{4 hIL 6 衰达水平的测定}

重组病毒 rAc・IL-6 感染 Sf9 细胞的 $48 \mathrm{~h}$ 培养 上清经 TTD 1 细胞 ${ }^{3} \mathrm{H}-\mathrm{TdR}$ 半数最高掺人法测定生 物活性为 $10^{6} \mathrm{u} / \mathrm{ml}$; 上清稀释 1000 倍经 ELISA 定 量测定 rhIL-6>1000pg/ml, 即表达水平大于 $1 \mu \mathrm{g} / \mathrm{ml}$ (图 8). 


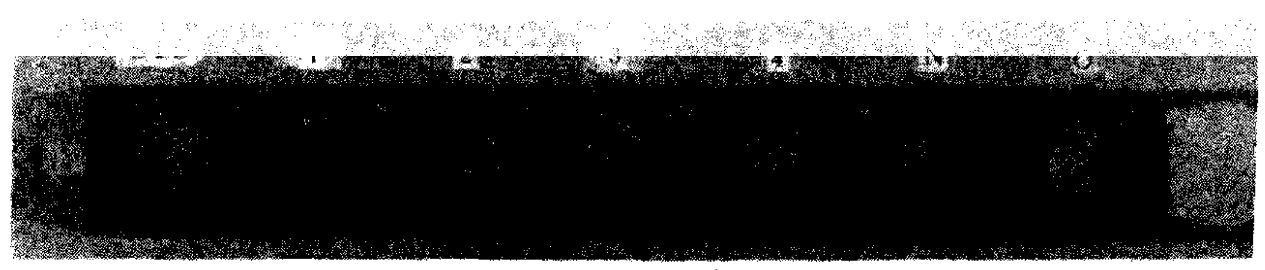

图 8 用 IL-6 ELISA 试剂盒检测 rhIL6表达水平

STD 一 - rhll-6 标准, $\mathrm{O}$ 一一培养基对照, N-wAcMNPV 阴性对照, 1-4 为检测样品

\section{3 讨 论}

\section{1 载体的选择}

本文之所以选择 pVL1393 作为 hIL-6 的表达载体是由于: (1) 此种非融合表达载体的表达 水平远高于其它非融合表达载体; (2) 含有多克隆位点容易定向克隆; (3) 重组载体 pVL・IL-6 与 wtAcMNPV 体内同源重组产生的重组病毒 rAc・IL-6 不需要辅助病毒便可直接感染昆虫细 胞 Sf 9 , 易于操作和获得高水平表达; (4)上游多角体基因序列相对完整, 因而稳态 mRNA 水平 高, 有利于高效表达 ${ }^{[13]}$.

\section{2 基因改构}

通过引物设计合成、PCR 扩增实现了对 hIL-6 cDNA 的下述改构: (1) 起始密码 ATG 周围 的序列 $\stackrel{-3}{\mathrm{GCTATGA}} \stackrel{+1}{+4}$ 中的 $\stackrel{-3}{\mathrm{G}} \rightarrow \mathrm{A}, \stackrel{-1}{\mathrm{~T}} \rightarrow \mathrm{C}, \stackrel{+4}{\mathrm{~A}} \rightarrow \mathrm{G}$, 从而使转译起始处于最优状态, 按 Kozak 报 道可提高表达水平 3-10 倍 ${ }^{[14]}$. 其中 $\stackrel{+4}{A} \rightarrow G$ 使 ATG 后的 AAC 变成 GAC, 因而使编码的 Asn 变为 Asp, 由于这个突变的氨基酸位于信号肽内, 所以对成熟的 hIL-6 活性无任何影响; (2) 增 加一个终止密码, 确保有效的转译终止; (3) 导人酶切位点便于定向重组. 上述改构经 DNA测 序准确无误. 在 PCR 产物的纯化过程中插人蛋白酶 $\mathrm{K}$ 处理 ${ }^{\left[{ }^{[}\right]}$, 是因为常规酚萃取很难去除粘 附于 PCR 产物末端的 Taq DNA 聚合酶, 这种残留之 Taq DNA 聚合酶干扰以后的酶切反应 而降低重组效率。

\section{3 重组病毒的监定}

重组病毒管选一般依据空斑形态学. AcMNPV 的多角体基因已测序并绘制图谱,而且证 明对病毒感染与复制并非必不可缺 ${ }^{[15]}$. 缺失或插人灭活多角体基因引起包含体阴性病毒的产 生, 并形成 $\mathrm{O} o c^{-}$空斑. $\mathrm{O} 0 c^{-}$空斑在形态上明显区别于野生型病毒形成的空斑 $000^{+}$, 为鉴定 用杂合基因取代 AcMNPV 多角体基因而产生的重组病毒提供了一条捷径. 本研究构建与篮 选出 rAc・IL-6 重组病毒, 感染 Sf9 细胞高效表达了有生物活性的 rhIL-6. 现正进行纯化及后 处理研究.

致谢 第四军医大学金伯泉教授, 解放军总医院李求是博士, 本室彭善云同志协助测定 rhIL-6 的生物活性, 在此一并致以诚揫的谢意. 


\section{各考文堿}

[1] Luckow, V. A., Recombinant DNA Technology and Applications (eds. Prokop, A., Bajpai, R. K., HO, C.), MoGraw-Hill, Inc. New York, 1991, 97-136.

[2] Hirano, T. et al, Immonology Today, 1990, 11:443-449.

[3] 王稁等等, 生物化学杂志, 1992, 8(2):242-246.

[4] 邹民吉等, 生物化学与生物物理进展, 1992, 19(4):319-321.

[ 5] Crowe, J. S. et al., Nucl. Acid. Res. 1991, 19(1): 184 .

[6] Sambrook, J., Fritsh, E. F., Maniatis, T., Molecular Cloning a Labonatory Mamual, 2nd ed., CSH, New York, 1989, $1.21-1.40,5.10,13.6-13.10$.

[7] Summers, M. D., Smith, G. E., A Mamual of Methods for Baculovirus Vector and Insect Cells Culture Procedures, 1987, $26-27$.

[8] Summers, M. D., Smith, G. E., A Manual of Methods for Baculovirus Vector and Insect Cells Culture Procedures, 1987, $29-30$.

[9] Summers, M. D., Smith, G. E., A Manual of Methods for Baculovirus Vector and Insect Cells Culture Procedures, 1987, $30-32$.

[10] Summers, M. D., Smith, G. E., A Manual of Methods for Baculovirus Vector and Insect Cells Culture Procedures, 1987, 22.

[11] 王青等, 中国兔疫学杂志, 1991, 7(6): 337一-343.

[12] 金伯泉，基础免度学实输指导，第四军医大学出版社，西安，1991，58一61.

[13] Luckow, V. A, Summers, M. D., Vinology, 1989, 170(5): 31-39.

[14] Kozak, M. et al., Cell, 1986, 44(2): 283-292.

[15] 侯云德, 分子病毒学, 学苑出版杜, 北京, $1990,72$. 